\title{
A Review of Pyrolysis Gasification of MSW
}

\author{
Ronghua Zeng ${ }^{1, a}$, Shuzhong Wang ${ }^{\star 2, b}$, Jianjun Cai ${ }^{3, c}$, Cao Kuang ${ }^{4, d}$ \\ 1,2,3,4 Key Laboratory of Thermo-Fluid Science and Engineering, Ministry of Education, School of \\ Energy and Power Engineering, Xi'an Jiaotong University, No.28 Xianning West \\ Road,Xi'an,Shaanxi, 170049, China \\ 2 Guangdong Xi'an Jiaotong University Academy, Foshan, Guangdong, 528000, PR China \\ asanjinse@126.com, bszwang@aliyun.com, ccaijianjun@stu.xjtu.edu.cn, \\ dkuangcao@stu.xjtu.edu.cn \\ ${ }^{*}$ is the Corresponding Author
}

\begin{abstract}
Keywords: Municipal Solid Waste Pyrolysis Gasification
Abstract. The pyrolysis gasification treatment in the paper is the new direction of municipal solid waste disposal by comparing waste incineration, composting and sanitary landfill treatment technology. The principle and classification of pyrolysis gasification technology are described in detail. The research status of three typical commercial waste disposal devices and pyrolysis gasification of domestic waste are introduced. The pyrolysis gasification temperature of waste is suitable between $700 \sim 900{ }^{\circ} \mathrm{C}$, the increase of gasification temperature can increase the yield and low calorific value of synthesis gas. Adding proper amount of water vapor to the gasification medium facilitates the cracking of the tar and improves the $\mathrm{H}_{2}$ content in the synthesis gas.
\end{abstract}

\section{Introduction}

With the industrialization and urbanization process, material consumption is increasing, the amount of urban living garbage increased dramatically, posing a serious threat to the ecological environment. In recent years, some of China's major cities in the production of garbage has been increasing, and more than 200 cities are surrounded by garbage, the total annual output of 2014 garbage reached 178 million tons, 2015 annual output of up to 191 million tons of garbage. China's large and medium-sized cities with an annual output of more than 100 million tons of waste, the vast majority of untreated accumulation in the suburbs, garbage collection of more than 70 million tons covers an area of 500 million square meters. Municipal solid waste is not just a waste, but garbage has a lot of organic matter --- it is a major renewable resource. Therefore, how to reduce the amount of garbage emissions, while using a certain waste disposal technology to achieve the garbage of the harmless, recycling of resources, turning waste into treasure, it has become China's waste and even the city in the process of facing an important issue.

By the end of December 2015, the total number of municipal solid waste treatment plants is 890 , garbage disposal capacity and harmless treatment capacity reached 576,800 tons/day, 180.1 million tons/year, the harmless treatment rate of solid waste Treatment rate has reached $94.1 \%$. At present, the traditional harmless treatment of municipal solid waste in China is sanitary landfill, composting and incineration. By 2015, sanitary landfill, composting and incineration accounted for $64 \%, 2 \%$ and $34 \%$ of the total sanitation treatment of municipal solid waste, respectively. In the traditional waste disposal method, the landfill operation is simple, wide adaptability, but the waste of land resources, and the existence of secondary pollution; composting cycle is long, the amount of treatment is small, the product is difficult to sell. Incineration technology has its significant 
reduction in capacity and the advantages of heat recovery, but the incineration process will produce a lot of acid gases, heavy metals and dioxins and so on. The method of pyrolysis gasification of municipal solid waste can eliminate the production of dioxin, and it has the characteristics of reducing capacity, making harmless, fully resourceful and secondary pollution, and is paying more and more attention $[1,2]$.

\section{Pyrolysis Gasification Technology of Municipal Solid Waste}

Pyrolysis gasification technology principle. Municipal solid waste pyrolysis is in the absence of oxygen or hypoxic conditions, the organic matter composition due to heat and chemical bond breakage, isomerization and other "thermal decomposition or cracking" reaction, from macromolecular organic matter into small molecules synthesis gas, tar and coke process. Garbage (including waste paper, plastic and other organic matter) containing high calorific value fuels can be treated with pyrolysis. Syngas was neutral in anaerobic or hypoxic conditions and can prevent the production of dioxins. Gasification is the process of adding the organic components of the waste to the gasification medium to produce the combustible mixture, tar and ash in the presence of the gasification medium. The gasification medium mainly includes air, oxygen-enriched gas, water vapor and carbon dioxide.

MSW pyrolysis gasification technology refers to the organic components in the waste under the conditions of hypoxia (excess air coefficient less than 1) high temperature chemical reaction, the formation of small molecules combustible gas as the main product of the thermal chemical conversion process, while generating part of the tar And solid residues [3]. The relationship between pyrolysis, gasification and combustion is shown in Fig. 1 [3]. Thermal conversion process and products is shown in Fig. 2 [4].

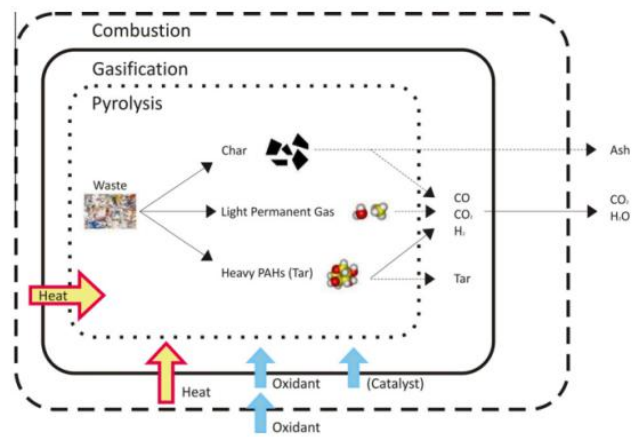

Fig.1.

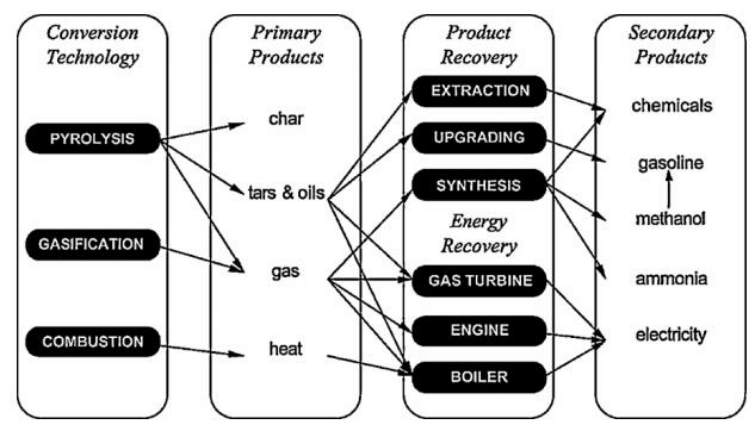

Fig.2.

Fig.1. The relationship between pyrolysis,gasification and combustion[3]

Fig.2. Thermal conversion process and products[4]

Pyrolysis gasification process. The process of MSW pyrolysis gasification includes four stages: drying, pyrolysis, oxidation and reduction, but the gasification process mainly occurs in the oxidation and reduction stage. Different stages of the gasification reactor in different distribution, in the fixed bed generally have a clear stage of distribution, and in the fluidized bed in the reaction phase of the boundaries are not clear. Different stages of the gasification reactor in different distribution, the reaction phase of the boundaries in the fixed bed generally have a clear stage of distribution, while not in the fluidized bed.

Pyrolysis gasification technology classification. MSW pyrolysis gasification technology can be classified from different angles, so it's a wide variety [5]. According to the heating method can be 
divided into direct heating method and indirect heating method, as shown in Figure 3; According to the different gasification reactor can be divided into fixed bed gasification (suction, suction and flat suction), fluidized bed gasification (bubbling and recycling); According to the different types of gasification medium can be divided into air gasification, oxygen gasification, steam gasification, hydrogen gasification, water vapor - oxygen gasification and water vapor - air mixing gasification, their respective characteristics is shown in Table 1 as shown.
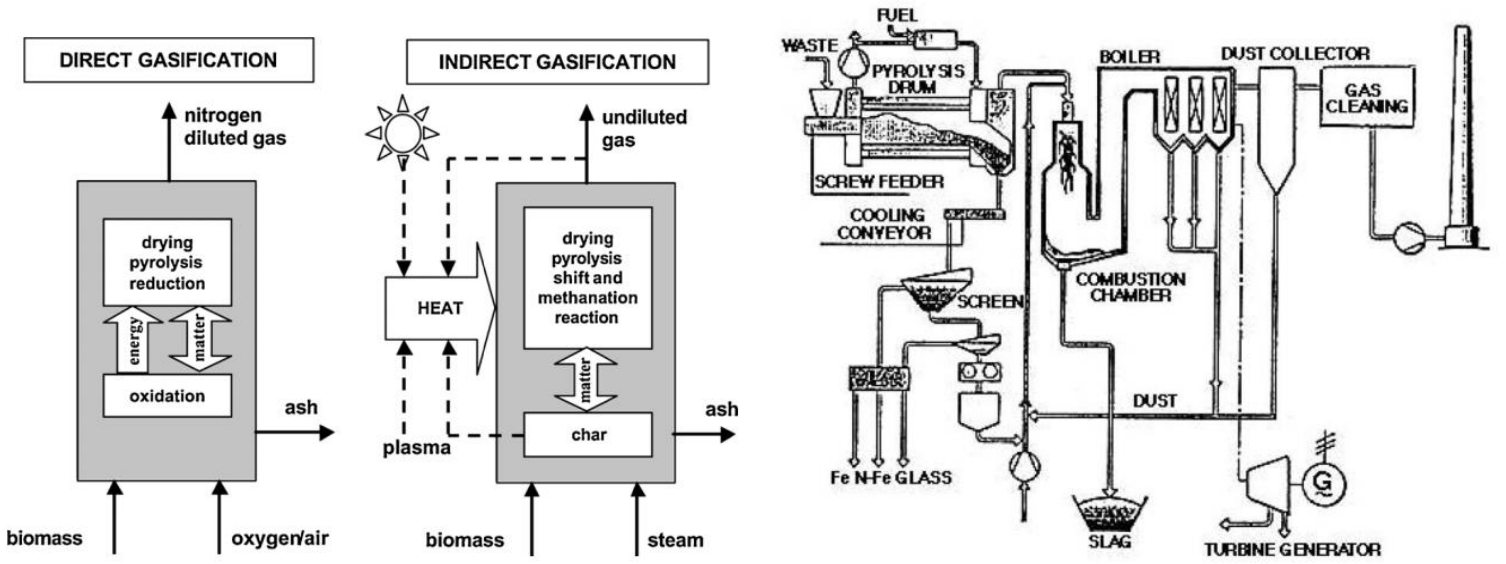

Fig.3. Direct and indirect gasfication process [4]

Fig.4. Siemens Schwel-Brenn Waste Pyrolysis Gasification Process [6]

Table 1 Comparison of gasification techniques using different gasification media

\begin{tabular}{|c|c|c|c|}
\hline $\begin{array}{l}\text { Gasification } \\
\text { medium }\end{array}$ & Features & $\begin{array}{l}\text { Synthetic } \\
\text { calorific } \\
\text { value } \\
{[\mathrm{MJ} / \mathrm{m} 3]}\end{array}$ & Disadvantages \\
\hline air & $\begin{array}{l}\text { self-heating gasification system, the most } \\
\text { simple and easy to achieve, the more } \\
\text { common application }\end{array}$ & $4.2 \sim 7.5$ & $\begin{array}{l}\mathrm{N} 2 \text { dilute the content of } \\
\text { combustible gas, so that calorific } \\
\text { value decreased }\end{array}$ \\
\hline oxygen & $\begin{array}{l}\text { the reaction rate is faster, the reactor solvent } \\
\text { is reduced, the thermal efficiency is high and } \\
\text { the gas quality is high }\end{array}$ & $10.92 \sim 18.9$ & $\begin{array}{l}\text { need to prepare pure oxygen, } \\
\text { consume a lot of energy, not } \\
\text { suitable for small business }\end{array}$ \\
\hline water vapor & $\begin{array}{l}\text { mainly in the endothermic process, the } \\
\text { gasification process need external heat } \\
\text { source, the reaction temperature should not } \\
\text { be too high }\end{array}$ & $10.92 \sim 18.9$ & $\begin{array}{l}\text { technology is complex, difficult to } \\
\text { control and operation }\end{array}$ \\
\hline $\begin{array}{l}\text { water vapor } \\
\text { - oxygen }\end{array}$ & $\begin{array}{l}\text { it is self-heating gasification system, no } \\
\text { external heat supply }\end{array}$ & 11.5 & ----- \\
\hline hydrogen & $\begin{array}{l}\text { hydrogen and carbon, water to produce large } \\
\text { amounts of methane }\end{array}$ & $\begin{array}{l}22.26 \sim 26.0 \\
4\end{array}$ & $\begin{array}{l}\text { reaction conditions harsh, the need } \\
\text { for high temperature and pressure } \\
\text { and hydrogen source }\end{array}$ \\
\hline
\end{tabular}




\section{Typical waste pyrolysis gasification process.}

MSW pyrolysis gasification technology research began in the 1970s, the purpose is to solve the oil crisis, to find new energy instead of fossil fuels. Europe, US, Japan and other developed countries have introduced a series of urban waste management regulations; due to garbage "reduction, harmless, resource-based" requirements, garbage gasification technology has been people's attention, become the focus of waste disposal technology research. After several decades of development, garbage pyrolysis gasification technology in developed countries has developed very mature, which is more representative of the Siemens Schwel-Brenn technology, the United States MTCI waste gasification process and the Thermoselect company's Thermoselect technology.

In the 1990s, Siemens developed the Schwel-Brenn pyrolysis gasification process, as shown in Figure 4 [6]. The process uses a non-continuous feed, consisting mainly of rotary kiln waste heat boilers, which operate at less than one atmospheric pressure. The waste is dried in an anaerobic environment by indirect hot pyrolysis $\left(450^{\circ} \mathrm{C}\right)$ for about one hour by external hot flue gas. The pyrolysis residue was then cooled to $150^{\circ} \mathrm{C}$ via a water bath and then melted by crushing at $300^{\circ}$ $\mathrm{C}$ under oxygen-enriched conditions. Water vapor can reach $400{ }^{\circ} \mathrm{C}$ and 40 atmospheres, power generation efficiency of $24 \%$. 1T MSW (Calorific value of $8.4 \mathrm{MJ} / \mathrm{kg}$ ) can produce $24.6 \mathrm{MW}$ of electricity, while generating $28 \mathrm{~kg}$ of iron and $4 \mathrm{~g}$ of non-ferrous metals (purity greater than $90 \%$ ), $140 \mathrm{~kg}$ of recyclable slag.

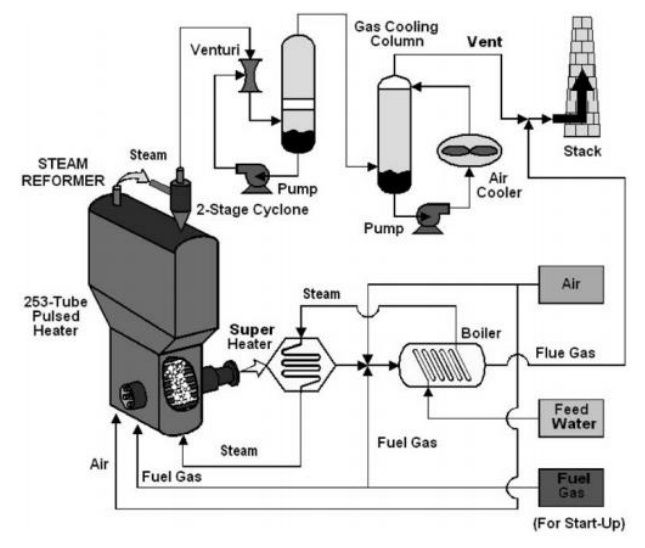

Fig.5

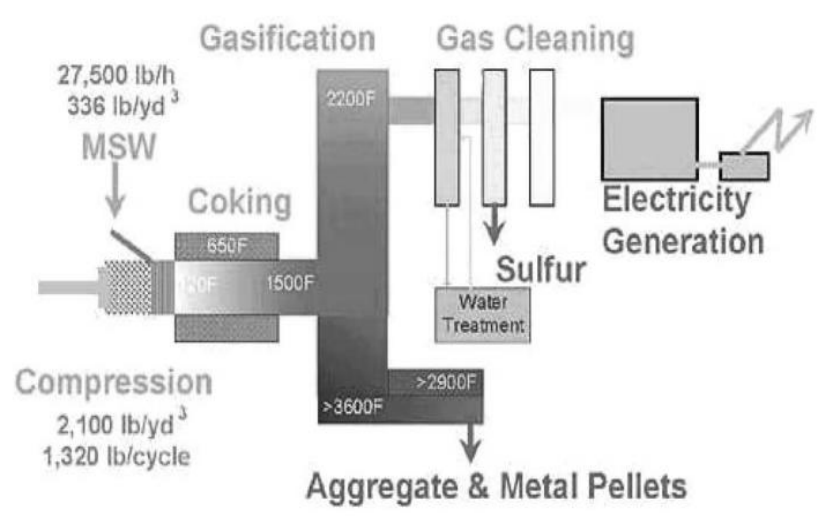

Fig.6

Fig.5 The United States MTCI waste gasification process [6]

Fig.6 Schematic of the Thermoselect Process [6]

The MTCI company developed a bubbling fluidized bed as the core gasification reactor waste gasification technology, the process shown in Figure 5 [6]. The MTCI steam reforming technique is designed in a bubbling fluidized bed reactor with a number of Helmholtz type resonant tube pulsed burners that provide the required gasification process by burning a portion of the syngas produced by the gasification of the waste energy. Application of this technology in the gasification of high ash, high alkali, rich in $\mathrm{Cl}, \mathrm{S}$ and heavy metals such as biomass and household waste and other waste, bubbling fluidized bed reactor temperature can reach $800 \sim 850{ }^{\circ} \mathrm{C}$. Most of the syngas produced by gasification can be used in the combustion of boilers, and this technology has been used in Canada, the United States and Germany.

Thermoselect process is shown in Fig.6 [6]. The process uses semi-continuous feeding, the first garbage into the hydraulic compression treatment, and then pushed into the horizontal channel; heating device outside the channel will be controlled at $600{ }^{\circ} \mathrm{C}$, the material within the tube pyrolysis reaction; pyrolysis products then enter the $800{ }^{\circ} \mathrm{C}$ Reaction zone, and finally reached $1200{ }^{\circ} \mathrm{C}$ high temperature furnace cavity gasification. VOC, PDDD / F were respectively cracked 
at the top and bottom temperatures of $2000^{\circ} \mathrm{C}$, respectively, and the molten residue was vitrified. The syngas rich in $\mathrm{CO}$ and $\mathrm{H} 2$ is cooled to $90{ }^{\circ} \mathrm{C}$ by water cooling, and the contaminants such as $\mathrm{CS} 2, \mathrm{HF}, \mathrm{H} 2 \mathrm{~S}$ and $\mathrm{HCl}$ are removed by two-stage wet process and activated carbon adsorption process. In 2004, Japan and Germany each had a 150t/d and 300t/d treatment capacity of the furnace in operation.

\section{Research Status of Domestic Waste Pyrolysis Gasification}

China's municipal solid waste components are roughly: organic $57 \%$, plastic $10 \%$, waste paper $8 \%$, glass $2 \%$, metal $1 \%$ and other $22 \%$. China is not classified for garbage disposal, the original garbage contains more impurities, lower calorific value $[7,8]$.Compared with traditional waste disposal (incineration, composting and sanitary landfill), the pyrolysis gasification of waste has the advantages of diversification of raw materials, low dioxin and acid gas content, but because of the complexity of the composition of household waste, there are some problems in the process of gasification. There are three problems in the process of pyrolysis and gasification of municipal solid waste: the tar is difficult to be removed in gasification syngas; the energy density of waste in China is low, component/calorific value is affected by seasonal effect and the scale of pyrolysis gasification is limited. The synthesis gas quality is not high, calorific value of about 7 9 MJ/Nm3 .

Liu et al. studied pyrolysis gasification of waste and concluded that the higher the gasification temperature and the smaller the particle size, the higher the synthesis gas and the $\mathrm{H} 2$ content.Gasification was carried out in a gasification reactor at $800^{\circ} \mathrm{C}$ and the yield of syngas is $0.31 \mathrm{Nm}^{3} / \mathrm{kg}$, tar is $32.5 \mathrm{~g} / \mathrm{Nm}^{3}$ and coke is $13.31 \mathrm{~g} / \mathrm{Nm}^{3}$ without catalyst. The yield of syngas was $0.31 \mathrm{Nm} 3 / \mathrm{kg}$ (H2 content $32.2 \%$, CO content $23.8 \%$, $\mathrm{CH} 4$ content $19.9 \%$, C2 hydrocarbon $2.1 \%$, CO2 content $21.3 \%$ ), the tar yield was $32.5 \mathrm{~g} / \mathrm{Nm}^{3}$ and the coke yield was $13.31 \mathrm{~g} / \mathrm{Nm}^{3}$ in the gasification reactor in $800{ }^{\circ} \mathrm{C}$ gasification reactor. Gasification process through the amount of water vapor can be syngas quality and yield, Liu and others get water vapor/material the best ratio is 1.33 [9].

Similarly, Luo and HE et al. also observed that the higher the gasification temperature, the greater the yield of syngas. Campus garbage air dry 7 days, garbage moisture content of $10.2 \%$. The carbon conversion increased from $65.5 \%$ to $84.87 \%$ when the temperature was increased from 700 ${ }^{\circ} \mathrm{C}$ to $900{ }^{\circ} \mathrm{C}$, and the temperature was increased from $700{ }^{\circ} \mathrm{C}$ to $900{ }^{\circ} \mathrm{C}$. The synthesis gas yield increased from $0.88\left(700^{\circ} \mathrm{C}\right) \mathrm{Nm}^{3} / \mathrm{kg}$ to $1.75\left(900^{\circ} \mathrm{C}\right) \mathrm{Nm} 3 / \mathrm{kg}$. When the gasification temperature is $900{ }^{\circ} \mathrm{C}$, the content of $\mathrm{H} 2$ is $54.22 \%$, the $\mathrm{CO}$ content is $22.72 \%$, the $\mathrm{CO} 2$ content is $20.61 \%$, the $\mathrm{CH} 4$ content is $1.33 \%$, the content of $\mathrm{C} 2 \mathrm{H} 4$ is $0.13 \%$, the content of $\mathrm{C} 2 \mathrm{H} 6$ is $0.99 \%$, and no tar exists in syngas [10].

HE et al. carried out on a fixed bed for MSW pyrolysis gasification experiments and observed that water vapor and calcined dolomite were promoted for the pyrolysis of tar [[10]]. Water vapor and catalyst, the tar content of $38.54 \mathrm{wt} \%$, in the steam gasification and no catalyst, the tar content of $18.75 \mathrm{wt} \%$; When the water vapor and catalyst are present, the tar content is 0 , but the low calorific value of the gasification syngas is reduced by $11.43 \mathrm{MJ} / \mathrm{Nm}^{3}$.

\section{Conclusions}

At present, the research of pyrolysis gasification in waste is mainly caused by air gasification. As the heat value of garbage itself is not high, the synthesis gas contains a large amount of N2 and CO2, and the heat value of synthesis gas is low and the limitation of utilization is large; On the other hand garbage pyrolysis gasification process requires a lot of heat, you need to add heat to the garbage 
heating, such as the use of coal heating, is easy to produce secondary pollution, the use of electricity and coal heating, the higher cost. According to the "Twelfth Five-Year Plan" statistics, straw reserves of 340 million tons, equivalent to 170 million tons of standard coal, forestry timber reserves of 350 million tons, equivalent to 200 million tons of standard coal. Municipal solid waste and biomass mixed pyrolysis gasification is a new direction to deal with waste pyrolysis gasification coking and improve the energy utilization of forestry wood. The pyrolysis gasification of waste is suitable for $700 \sim 900{ }^{\circ} \mathrm{C}$, the higher the temperature, the higher the synthesis gas and the lower calorific value.

\section{Acknowledgements}

The authors gratefully acknowledge the financial supports for this research by Guangdong Province Science and Technology Planning Project of China (2017A010104020).

\section{References}

[1] Jackson D V. 1992 Resources recovery, agricultural industrial and municipal waste management [M]. London: Mech Engr Pub Ltd

[2] Heek K H, Strobel B O, Wanzl W. 1994 Coal utilization process and their application to waste recycling and biomass conversion [J]. Fuel, 73(7):1135 1143

[3] Arena, U. (2012). Process and technological aspects of municipal solid waste gasification. a review. Waste Management, 32(4), 625.

[4] Singh, R. P., Tyagi, V. V., Allen, T., Ibrahim, M. H., \& Kothari, R. (2011). An overview for exploring the possibilities of energy generation from municipal solid waste (msw) in indian scenario. Renewable \& Sustainable Energy Reviews, 15(9), 4797-4808.

[5] He, M., Xiao, B., Liu, S., Guo, X., Luo, S., \& Xu, Z., et al. (2009). Hydrogen-rich gas from catalytic steam gasification of municipal solid waste $(\mathrm{msw})$ : influence of steam to $\mathrm{msw}$ ratios and weight hourly space velocity on gas production and composition. International Journal of Hydrogen Energy, 34(5), 2174-2183.

[6] Malkow, T. (2004). Novel and innovative pyrolysis and gasification technologies for energy efficient and environmentally sound msw disposal. Waste Management, 24(1), 53-79.

[7] Chen, X., Geng, Y., \& Fujita, T. (2010). An overview of municipal solid waste management in china. Waste Management, 30(4), 716-24.

[8] Zheng, L., Song, J., Li, C., Gao, Y., Geng, P., \& Qu, B., et al. (2014). Preferential policies promote municipal solid waste (msw) to energy in china: current status and prospects. Renewable \& Sustainable Energy Reviews,36(C), 135-148.

[9] Liu Jianjun. Experimental Study on Catalytic Gasification of Municipal Solid Waste to Produce Gas. (Doctoral dissertation, Wuhan Institute of Technology). 2011

[10] He, M., Hu, Z., Xiao, B., Li, J., Guo, X., \& Luo, S., et al. (2009). Hydrogen-rich gas from catalytic steam gasification of municipal solid waste $(\mathrm{msw})$ : influence of catalyst and temperature on yield and product composition. International Journal of Hydrogen Energy,34(1), 195-203. 